\section{Neurociência, livre-arbítrio e a possibilidade da discussão bioética}

Félix, Francisco Hélio Cavalcante

Bacharel em Medicina pela Universidade Federal do Ceará - UFC, Brasil; Bacharel em Direito pela Universidade Federal do Ceará - UFC, Brasil; Mestre em Filosofia pela Universidade Federal do Ceará - UFC, Brasil. Endereço para contato:fhcfelix@gmail.com

PALAVRAS-CHAVE: Livre-arbítrio. Neurociência. Bioética. Filosofia da Ação.

Durante o transcorrer do século XX e o começo do século XXI, a Bioética se fortaleceu e se consolidou como importante instrumento de análise de questões consideradas cruciais. Trata-se de um campo interdisciplinar que tangencia as Ciências, a Filosofia, o Direito, entre outras áreas. Tornouse elemento inescapável de discussões acerca de temas ligados ao ser humano, em sua interação com seus semelhantes e com o meio ambiente. A possibilidade de discussão acerca da Ética e da Bioética pressupõe, contudo, que este ser humano seja um sujeito dotado de autonomia e de capacidade de escolha. A própria caracterização do desrespeito aos Direitos Humanos depende da existência de um agente autônomo e responsável por seus atos. A crença na possibilidade dessa liberdade de ação é a regra para a maioria das pessoas. Alguns avanços da Neurociência, entretanto, parecem desafiar a noção comum de que o sujeito pode escolher, de modo consciente e livre, acerca de como e quando agir. Experimentos do fisiologista Benjamin Libet [1], realizados no final do século XX, mostraram evidências de que o processo cerebral responsável pelo ato considerado voluntário tem início antes mesmo da consciência da decisão de realizar este ato. Libet defendia que o indivíduo poderia, na verdade, vetar o ato, assim que dele tomasse consciência, tendo cerca de 200 milissegundos para tal. Aí residiria seu livre-arbítrio. À época, seu trabalho suscitou polêmica e foi criticado por suas limitações técnicas. Recentemente, replicações do modelo experimental de Libet utilizando novos métodos de registro de atividade cerebral [2] reacenderam a discussão acadêmica acerca da possibilidade de livre-arbítrio, pois mostraram atividade cerebral ligada a um movimento considerado voluntário até vários segundos antes da decisão consciente de mover [3]. Sua ideia de veto possível, por outro lado, perdeu força, por não ser facilmente testável. Diante de uma autonomia de agir posta em dúvida de modo mensurável e replicável, a própria possibilidade de discussão acerca da Ética em geral e da Bioética em particular resta desafiada [4]. Outrossim, um dos principais objetos da própria Bioética, a Neurociência, aparenta ser um risco a sua capacidade de erigir um discurso coerente, este baseado, em boa parte, na autonomia do ser humano. Um dos fundamentos da Bioética é, deste modo, colocado em xeque.
Essa questão, agora renovada por crescentes avanços tecnológicos, alimenta discussões importantes no âmbito da Filosofia da Ação e da Filosofia da Mente. Alfred Mele [5], por exemplo, defende que uma distinção entre intenções proximais e distais, além do conceito de intenções efetivas, poderiam resolver essa questão. Apesar da sofisticação e da coerência interna de seu modelo, a relação causal entre uma decisão, o processo cerebral correspondente e a própria ação ainda não parece ser testável nele. $O$ objetivo do trabalho é mostrar, a partir de algumas das principais linhas de discussão atuais a respeito do livre-arbítrio, que a questão ainda permanece em aberto, havendo alguns estudos promissores sobre o tema, mas que não chegam a compor uma solução completa da questão, diante dos avanços da Neurociência e de seus desafiadores achados.

\section{REFERÊNCIAS}

[1] Libet B, Gleason CA, Wright EW, Pearl DK. Time of conscious intention to act in relation to onset of cerebral activity (readiness-potential). The unconscious initiation of a freely voluntary act. Brain 1983 Sep;106(Pt 3):623-42.

[2] Fried I, Mukamel R, Kreiman G. Internally generated preactivation of single neurons in human medial frontal cortex predicts volition. Neuron 2011 Feb;69(3):548-62.

[3] Bode S, He AH, Soon CS, Trampel R, Turner R, Haynes JD. Tracking the unconscious generation of free decisions using ultra-high field fMRI. PloS one 2011;6(6):e21612.

[4] Bode S, Murawski C, Soon CS, Bode P, Stahl J, Smith PL. Demystifying "free will": The role of contextual information and evidence accumulation for predictive brain activity. Neuro Bio Rev 2014 Nov;47:636-45.

[5] Mele A. Effective Intentions. New York: Oxford University Press; 2009. 